\title{
Detection level and pattern of positive lesions using PSMA PET/CT for staging prior to radiation therapy
}

Nina-Sophie Schmidt-Hegemann ${ }^{1 \dagger}$, Wolfgang Peter Fendler ${ }^{2 \dagger}$, Alexander Buchner ${ }^{3}$, Christian Stief ${ }^{3}$, Paul Rogowski ${ }^{1}$, Maximilian Niyazi ${ }^{1}$, Chukwuka Eze ${ }^{1}$, Minglun Li ${ }^{1}$, Peter Bartenstein² ${ }^{2}$ Claus Belka ${ }^{1}$ and Ute Ganswindt ${ }^{1,4^{*}}$

\begin{abstract}
Background: To determine the potential role of ${ }^{68} \mathrm{Ga}-\mathrm{PSMA}$ positron emission tomography/computed tomography (PET/CT) in radiotherapy (RT) planning for prostate cancer (PCa).

Methods: One hundred twenty-nine patients (pts) with ${ }^{68} \mathrm{Ga}-\mathrm{PSMA}$ PET/CT were retrospectively analysed. Potentially influencing factors (androgen deprivation therapy, amount of ${ }^{68} \mathrm{Ga}$-PSMA-HBED-CC, PSA doubling time $\leq />10$ months, PSA before PET/CT, T-/N-category and Gleason score) were evaluated by logistic regression analysis. The detection rate of PSMA PET/CT was compared to contrast enhanced CT and its impact on RT management analysed.

Results: One hundred twenty-nine patients (pts) (20 at initial diagnosis, 49 with PSA relapse and 60 with PSA persistence after radical prostatectomy) received PSMA PET/CT prior to RT. The majority of pts. (71.3\%) had PET-positive findings ( $55.1 \%$ of pts. with PSA recurrence, $75 \%$ of pts. with PSA persistence and $100 \%$ of newly diagnosed pts). Median PSA before PET/CT in pts. with pathological findings $(n=92)$ was $1.90 \mathrm{ng} / \mathrm{ml}$ and without $(n=37) 0$. $30 \mathrm{ng} / \mathrm{ml}$. PSA level at time of PET/CT was the only factor associated with PET-positivity. In pts. with a PSA $\leq 0.2 \mathrm{ng} / \mathrm{ml}$, the detection rate of any lesion was $33.3 \%$, with a PSA of $0.21-0.5 \mathrm{ng} / \mathrm{ml} 41.2 \%$ and with a PSA of $0.51-1.0 \mathrm{ng} / \mathrm{ml} 69$. $2 \%$, respectively. Regarding the anatomic distribution of lesions, $42.2 \%$ and $14.7 \%$ of pts. with relapse or persistence had pelvic lymph node and distant metastases. In pts. at initial diagnosis the detection rate of pelvic lymph nodes and distant metastases was $20 \%$ and $10 \% .{ }^{68} \mathrm{Ga}$-PSMA PET/CT had a high detection rate of PCa recurrence outside the prostatic fossa in pts. being considered for salvage RT (22.4\% PET-positive pelvic lymph nodes and $4.1 \%$ distant metastases). Compared to CT, PSMA PET/CT had a significantly higher sensitivity in diagnosing rates of local recurrence/primary tumour (10.1\% vs. $38 \%)$, lymph nodes (15.5\% vs. $38.8 \%)$ and distant metastases (5.4\% vs. $14.0 \%)$. This resulted in a modification of RT treatment in $56.6 \%$ of pts.
\end{abstract}

Conclusions: The detection of PCa is strongly associated with PSA level at time of ${ }^{68}$ Ga-PSMA PET/CT. PSMA PET/CT differentiates between local, regional and distant metastatic disease with implications for disease management. PSMA PET/CT allows for tumour detection in post-prostatectomy pts. with PSA $\leq 0.5 \mathrm{ng} / \mathrm{ml}$ considered for salvage RT.

Keywords: ${ }^{68} \mathrm{Ga}-\mathrm{PSMA}$ PET/CT, Prostate cancer, Radiotherapy, Radical prostatectomy

\footnotetext{
* Correspondence:

Ute.Ganswindt@med.uni-muenchen.de; ute.ganswindt@i-med.ac.at

Nina-Sophie Schmidt-Hegemann and Wolfgang Peter Fendler are equal

contributors.

${ }^{\dagger}$ Equal contributors

'Department of Radiation Oncology, University Hospital, LMU Munich,

Munich, Germany

${ }^{4}$ Department of Therapeutic Radiology and Oncology, Innsbruck Medical

University, Anichstr. 35, A-6020 Innsbruck, Austria

Full list of author information is available at the end of the article
} 


\section{Background}

A precise detection and visualisation of disease extent is of essential importance for indication and target volume definition in radiotherapy of prostate cancer. Due to limitations in sensitivity and specificity, MRI and choline PET/CT are not considered precise enough especially at PSA levels $\leq 1 \mathrm{ng} / \mathrm{ml}[1,2]$, although both imaging modalities are as well capable of modifying treatment approaches [3-7]. Recently, a ${ }^{68}$ Ga-labelled PSMA-targeted ligand with high affinity to prostate-specific membrane antigen (PSMA), a cell surface protein overexpressed in prostate cancer cells has been introduced for positron emission tomography (PET) imaging [8-11]. PET with ${ }^{68} \mathrm{Ga}$-PSMA demonstrated a superior tumour-tobackground signal intensity and substantially higher detection rates than have been previously reported for other imaging modalities in patients with newly diagnosed [12-15] or recurrent [3, 16-20] prostate cancer. From surgical series, it is known that ${ }^{68} \mathrm{Ga}$-PSMA positron emission tomography/computed tomography (PET/CT) allows for a highly correct identification of lymph node metastases with a sensitivity and specificity ranging from $66 \%$ to $84 \%$ and $82 \%$ to $99 \%$ [14, 15], respectively. However, there is a substantial percentage of prostate cancer patients with a negative ${ }^{68} \mathrm{Ga}$-PSMA PET/ CT. Bearing this in mind, we tried to determine retrospectively which factors correlate with a positive ${ }^{68} \mathrm{Ga}$ PSMA PET/CT in patients with primary, persistent or recurrent prostate cancer. Furthermore, we compared the detection rate of ${ }^{68} \mathrm{Ga}-\mathrm{PSMA} \mathrm{PET} / \mathrm{CT}$ to contrast enhanced CT and analysed its impact on the decisionmaking process within our department of radiation oncology. Several clinical scenarios may be distinguished: A PET-positive local recurrence within the prostatic fossa might justify a simultaneous integrated boost and an additional antiandrogen therapy. Likewise, PET-positive pelvic lymph node metastases might be treated with an enlargement of the clinical target volume, a focally higher dose and antiandrogen therapy. In addition, the evidence of distant metastases might even cause a non-realisation of a planned radiotherapy treatment.

\section{Methods}

\section{Study population}

${ }^{68} \mathrm{Ga}$-PSMA PET/CT has been routinely offered to patients for prostate cancer staging before radiotherapy in our clinic (February 2014-August 2016). A total of 129 patients consecutively received ${ }^{68} \mathrm{Ga}$-PSMA PET/CT prior to radiotherapy in different clinical scenarios: 20 patients at initial diagnosis (mostly high-risk patients with suspected extra-prostatic manifestations), 60 with biochemical persistence after radical prostatectomy and 49 with biochemical relapse (Table 1). All patients gave written informed consent to undergo ${ }^{68} \mathrm{Ga}$-PSMA PET/
Table 1 Patients' characteristics

\begin{tabular}{|c|c|c|c|c|}
\hline Characteristic & All pts. & $\begin{array}{l}\text { Initial } \\
\text { diagnosis }\end{array}$ & $\begin{array}{l}\text { PSA } \\
\text { relapse }\end{array}$ & $\begin{array}{l}\text { PSA } \\
\text { persistence }\end{array}$ \\
\hline Number & 129 & 20 & 49 & 60 \\
\hline Age (years; median, range) & $72(47-86)$ & $76(53-86)$ & $74(50-83)$ & $69(47-83)$ \\
\hline \multicolumn{5}{|l|}{ Gleason Score [pts] } \\
\hline 6 & $11(8.5 \%)$ & $3(15 \%)$ & $7(14.3 \%)$ & $1(1.7 \%)$ \\
\hline $7 a$ & $27(20.9 \%)$ & $3(15 \%)$ & 19 (38.8\%) & $5(8.3 \%)$ \\
\hline $7 b$ & $37(28.7 \%)$ & $6(30 \%)$ & $11(22.4 \%)$ & $20(33.3 \%)$ \\
\hline 8 & $18(14 \%)$ & $3(15 \%)$ & $7(14.3 \%)$ & $8(13.3 \%)$ \\
\hline 9 & $34(26.4 \%)$ & $5(25 \%)$ & $5(10.2 \%)$ & $24(40.0 \%)$ \\
\hline 10 & $2(1.6 \%)$ & - & - & $2(3.3 \%)$ \\
\hline \multicolumn{5}{|l|}{ Risk group (D'Amico) [pts] } \\
\hline low & $5(3.9 \%)$ & $1(5.0 \%)$ & $3(6.1 \%)$ & $1(1.7 \%)$ \\
\hline intermediate & $21(16.3 \%)$ & $2(10.0 \%)$ & $13(26.5 \%)$ & $6(10.0 \%)$ \\
\hline high & $103(79.8 \%)$ & $17(85 \%)$ & $33(67.3 \%)$ & $53(88.3 \%)$ \\
\hline PSMA PET positive [pts] & $92(71.3 \%)$ & $20(100 \%)$ & $27(55.1 \%)$ & $45(75 \%)$ \\
\hline $\begin{array}{l}\text { PSA PRE-PSMA PET } \\
{[\mathrm{ng} / \mathrm{ml} \text { (median/ }} \\
\text { mean, range) }\end{array}$ & $\begin{array}{l}0.86 / 6.04 \\
(0.13-150.00)\end{array}$ & $\begin{array}{l}12.4 / 27.28 \\
(0.14-150.0)\end{array}$ & $\begin{array}{l}0.49 / 1.00 \\
(0.15-6.24)\end{array}$ & $\begin{array}{l}0.99 / 3.08 \\
(0.13-39.2)\end{array}$ \\
\hline \multicolumn{5}{|l|}{ PSA doubling time } \\
\hline$\leq 10$ months & $81(74.3 \%)$ & - & $21(42.9 \%)$ & $60(100 \%)$ \\
\hline$>10$ months & $28(25.7 \%)$ & - & $28(57.1 \%)$ & - \\
\hline ADT at time of PET [pts] & $14(10.9 \%)$ & $2(10 \%)$ & $4(8.2 \%)$ & $8(13.3 \%)$ \\
\hline $\begin{array}{l}\text { Activity of } 68 \mathrm{Ga}-\mathrm{PSMA}- \\
\text { HBED-CC }[\mathrm{MBq}] \\
\text { (mean, range) }\end{array}$ & $\begin{array}{l}190.43 \\
(87-293)\end{array}$ & $\begin{array}{l}197.50 \\
(100-293)\end{array}$ & $\begin{array}{l}192.07 \\
(94-293)\end{array}$ & $\begin{array}{l}186.85 \\
(87-286)\end{array}$ \\
\hline
\end{tabular}

(Pts patients, PSA prostate specific antigen, $A D T$ androgen deprivation therapy, $M B q$ Mega-Becquerel)

CT. This retrospective analysis is in compliance with the principles of the Declaration of Helsinki and its subsequent amendments [21] and was approved by the Ethics Committee of the LMU Medical Faculty .

\section{PSMA ligand and PET/CT imaging}

PSMA-HBED-CC was radiolabelled with ${ }^{68} \mathrm{Ga}^{3+}$ from a ${ }^{68} \mathrm{Ge} /{ }^{68} \mathrm{Ga}$ generator system (GalliaPharm, Eckert \& Ziegler AG, Berlin, Germany) using an automated synthesis module (GRP, Scintomics $\mathrm{GmbH}$, Munich, Germany) and pre-packed cassettes (ABX $\mathrm{GmbH}$, Radeberg, Germany) as described previously for a different PSMA ligand by Weineisen et al. [22]. ${ }^{68} \mathrm{Ga}$ PSMA PET/CT images extending from the base of the skull to the mid-thigh were acquired. PET/CT scan was obtained with intravenous injection of iodinecontaining contrast agent (Ultravist 300, Schering, Berlin, Germany; or Imeron 300, Bracco, Konstanz; $2.5 \mathrm{~mL} / \mathrm{s}$; in portal venous phase) $60 \mathrm{~min}$ after almost simultaneous intravenous administration of $20 \mathrm{mg}$ furosemide and ${ }^{68} \mathrm{Ga}-\mathrm{PSMA}$ (median 189 megabecquerel (MBq), range 87-293). Directly prior to the PET/CT scan, patients were asked to empty their bladder to minimise tracer accumulation. 


\section{Image interpretation}

PET/CT was interpreted by a consensus read of one nuclear medicine physician and one radiologist. Location of lesions was each determined by CT. PET-positive lesions were identified by ${ }^{68}$ Ga-PSMA uptake visually above background and not associated with the physiologic uptake. CT-positive nodes were defined by increased short axis diameter, loss of fatty hilum, or increased contrast enhancement. Bone metastases were detected by suspicious sclerotic lesions, visceral metastases by suspicious hypodense or hyperdense lesions in the respective organ. Based on PET/CT images and reports, stage according to PET or CT was documented separately by one nuclear medicine physician and one radiation oncologist [23].

\section{Statistical analysis}

Demographic and tumour characteristics were analysed. The association between positive ${ }^{68} \mathrm{Ga}$-PSMA PET/CT findings and possibly interacting variables, like androgen deprivation therapy (ADT) at the time of PET/CT, amount of injected tracer, PSA-level, PSA doubling time, $\mathrm{T}-/ \mathrm{N}$-category and Gleason score was assessed by univariate and multivariate logistic regression analysis. $P$ values $<0.05$ were considered statistically significant. PSA before PET/CT was classified in eight steps ( $\leq$ $0.2 \mathrm{ng} / \mathrm{ml}->20 \mathrm{ng} / \mathrm{ml})$. Gleason score was grouped in six different classes (GS 5/6, GS 7a, GS 7b, GS 8, GS 9 and GS 10), T-category in four (T1 - T4) and Ncategory in three classes (N0, N1, Nx). Injected tracer amount was evaluated as multiples of $100 \mathrm{MBq}$. Patients after radical prostatectomy were classified by PSA doubling time $\leq$ vs. $>10$ months. $\mathrm{PET} / \mathrm{CT}$ positive findings (primary tumour/local recurrence, lymph node and distant metastases) are presented separately according to the respective treatment indication prior to radiotherapy. The detection rate of residual tumour, recurrence or newly diagnosed disease comparing PET/CT to CT exclusively as well as change in radiotherapy management was analysed by Fisher's test.

\section{Results}

A total of 129 patients (20 at initial diagnosis, 60 with biochemical persistence and 49 with biochemical relapse after radical prostatectomy) consecutively received ${ }^{68} \mathrm{Ga}$ PSMA PET/CT prior to radiotherapy (Table 1). Most patients (71.3\%) had ${ }^{68} \mathrm{Ga}$-PSMA PET/CT-positive findings: Patients with biochemical recurrence had the lowest detection rate $(55.1 \%)$ followed by patients with biochemical persistence (75\%). At initial diagnosis, all patients (100.0\%) had ${ }^{68}$ Ga-PSMA PET/CT-positive findings. Overall, the predominant GS, T- and Ncategory were 7b, T3 and N0 - in newly diagnosed patients prior to definitive radiotherapy $7 \mathrm{~b}, \mathrm{cT} 1 / \mathrm{cT} 3$ and cN0, in patients with biochemical relapse $7 \mathrm{a}, \mathrm{pT} 2$ and
pN0 and in patients with biochemical persistence 9, pT3 and $\mathrm{pN} 1$, respectively. Altogether, most patients had a high-risk prostate cancer (79.8\%) according to D'Amico risk group classification [24]. PSA doubling time in postprostatectomy patients differed between patients with biochemical recurrence having mainly a PSA doubling time $>10$ months $(57.1 \%)$ versus patients with biochemical persistence having a PSA doubling time $\leq 10$ months (100\%). ADT was in use in 14 patients at the time of ${ }^{68} \mathrm{Ga}$ PSMA PET/CT. Median PSA before ${ }^{68}$ Ga-PSMA PET/CT was $12.4 \mathrm{ng} / \mathrm{ml}$ in newly diagnosed patients, $0.99 \mathrm{ng} / \mathrm{ml}$ in patients with biochemical persistence and $0.49 \mathrm{ng} / \mathrm{ml}$ in patients with biochemical recurrence.

\section{Factors predicting ${ }^{68} \mathrm{Ga}$-PSMA PET/CT positive findings}

Patients with pathological radiotracer uptake $(n=92$; Table 2) had a median PSA of $1.90 \mathrm{ng} / \mathrm{ml}$ (range 0.14150.0), a PSA doubling time of mainly $\leq 10$ months (77.8\%), mainly a T3 N0 prostate cancer, a predominant GS 9 (29.3\%) and ongoing ADT at time of PET in 12 patients. They were injected with a mean activity of $191.96 \mathrm{MBq}{ }^{68} \mathrm{Ga}-\mathrm{PSMA}-H B E D-C C$ (range 87-293) and were mainly high-risk patients $(81.5 \%)$. Patients without pathological findings $(n=37$; Table 2$)$ had a median PSA of $0.30 \mathrm{ng} / \mathrm{ml}$ (range $0.13-3.24$ ), a PSA doubling

Table 2 Patient characteristics: PET positive vs. PET negative

\begin{tabular}{|c|c|c|}
\hline Characteristic & PET positive & PET negative \\
\hline Number & 92 & 37 \\
\hline $\begin{array}{l}\text { Age (years) at PSMA PET } \\
\text { (median, range) }\end{array}$ & $72(49-86)$ & $72(47-80)$ \\
\hline \multicolumn{3}{|l|}{ Gleason Score [pts] } \\
\hline 6 & $8(8.7 \%)$ & $3(8.1 \%)$ \\
\hline $7 a$ & $19(20.7 \%)$ & $8(21.6 \%)$ \\
\hline $7 b$ & $23(25.0 \%)$ & $14(37.8 \%)$ \\
\hline 8 & $13(14.1 \%)$ & $5(13.5 \%)$ \\
\hline 9 & $27(29.3 \%)$ & $7(18.9 \%)$ \\
\hline 10 & $2(2.2 \%)$ & - \\
\hline \multicolumn{3}{|l|}{ Risk group (D’Amico) [pts] } \\
\hline low & $3(3.3 \%)$ & $2(5.4 \%)$ \\
\hline intermediate & $14(15.2 \%)$ & 7 (18.9\%) \\
\hline high & 75 (81.5\%) & $28(75.7 \%)$ \\
\hline $\begin{array}{l}\text { PSA PRE-PSMA PET }[\mathrm{ng} / \mathrm{ml}] \\
\text { (median/mean, range) }\end{array}$ & 1.90/8.27 (0.14-150.0) & $0.30 / 0.50(0.13-3.24)$ \\
\hline \multicolumn{3}{|l|}{ PSA doubling time } \\
\hline$\leq 10$ months & $56(77.8 \%)$ & $25(67.6 \%)$ \\
\hline$>10$ months & $16(22.2 \%)$ & $12(32.4 \%)$ \\
\hline ADT at time of PET [pts] & $12(13.0 \%)$ & $2(5.4 \%)$ \\
\hline $\begin{array}{l}\text { Activity of 68Ga-PSMA-HBED- } \\
\text { CC [MBq] (mean, range) }\end{array}$ & $191.96(87-293)$ & $186.78(94-293)$ \\
\hline
\end{tabular}

(Pts patients, PSA prostate specific antigen, ADT androgen deprivation therapy, $M B q$ Mega-Becquerel) 
time of mainly $\leq 10$ months (67.6\%), mainly a T3 N0 prostate cancer and a predominant GS 7b. Mean activity of ${ }^{68} \mathrm{Ga}$-PSMA-HBED-CC radiotracer was $186.78 \mathrm{MBq}$ (range 94-293) in PET-negative patients with patients being mostly high-risk patients $(75.7 \%)$ and two patients having ongoing ADT at the time of PET scan. In the univariate analysis (Table 3) no significant difference was found between PET-positive and PET-negative patients regarding the use of ADT at time of PET $(p=0.222)$, the injected amount of ${ }^{68}$ Ga-PSMA-HBED-CC $(p=0.590)$, the PSA doubling time $\leq />10$ months $(p=0.517)$, GS $(p=0.285)$ and T- $(p=0.982)$ and N-category $(p=0.987)$. Concerning PSA before PET, a significant difference was found $(p<0.001)$. In the multivariate analysis, the significant association between a PETpositive result and PSA level a time of PET persisted $(p=0.002)$. Figures 1 and 2 demonstrate the probability of pathological ${ }^{68} \mathrm{Ga}$-PSMA PET/CT depending on PSA level at time of PET/CT and GS. There is an almost linear increase of PET-positive result with rising PSA level: Patients with PSA $\leq 0.2 \mathrm{ng} / \mathrm{ml}$ had a detection rate of $33.3 \%$, patients with PSA $0.21 \leq 0.5 \mathrm{ng} / \mathrm{ml}$ a rate of $41.2 \%$ and patients with PSA $0.51 \leq 1.0 \mathrm{ng} / \mathrm{ml}$ a rate of $69.2 \%$.

\section{Tumour location and PET versus CT-positive findings}

Prior to definitive radiotherapy, ${ }^{68}$ Ga-PSMA PET/CT showed suspicious lesions within the prostate gland in $90 \%$ of patients and suspicious pelvic lymph nodes and/ or distant metastases in $20 \% / 10 \%$ of the patients, respectively. ${ }^{68}$ Ga-PSMA PET/CT had a high detection rate of prostate cancer recurrence outside the prostatic fossa in patients being considered for salvage radiotherapy: $22.4 \%$ of patients had PET-positive pelvic lymph nodes and $4.1 \%$ distant metastases. Both patients with distant metastases had also local recurrence exclusively without evidence of pelvic lymph node metastases. In patients considered for salvage radiotherapy with a PSA $<0.5 \mathrm{ng} / \mathrm{ml}$ (25 patients), ${ }^{68}$ Ga-PSMA PET/CT

Table 3 Univariate and multivariate analysis of factors predicting 68Ga-PSMA PET/CT positive findings

\begin{tabular}{|c|c|c|c|}
\hline $\begin{array}{l}\text { Association between PET } \\
\text { positive results and }\end{array}$ & Present (yes/no) & $p$-Value ${ }^{a}$ & $p$-Value \\
\hline ADT & No & 0.222 & 0.321 \\
\hline $\begin{array}{l}\text { Activity of 68Ga-PSMA- } \\
\text { HBED-CC [MBq] }\end{array}$ & No & 0.590 & 0.843 \\
\hline PSA PRE-PSMA PET & Yes & $<0.001^{*}$ & $0.002^{*}$ \\
\hline $\begin{array}{l}\text { PSA doubling time } \leq /> \\
10 \text { months }\end{array}$ & No & 0.517 & 0.942 \\
\hline Gleason Score & No & 0.285 & 0.482 \\
\hline
\end{tabular}

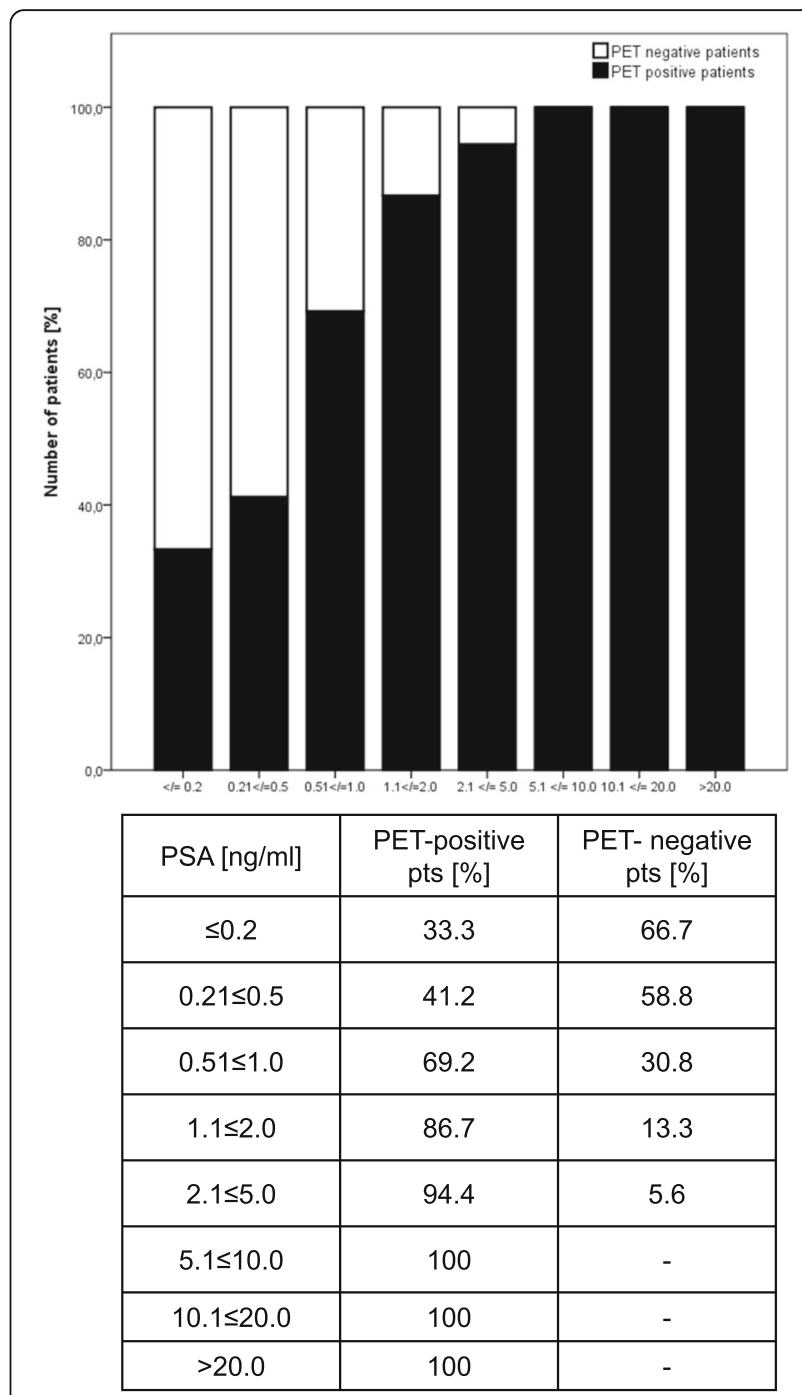

Fig. 1 Probability of a pathological ${ }^{68} \mathrm{Ga}-\mathrm{PSMA}$ PET/CT depending on PSA levels in 129 patients. Corresponding table shows the rates of PET/CTs with/without pathological radiotracer uptake in \% according to PSA level

detected in $16.0 \%$ local recurrences within the prostatic fossa and in 20.0\% PET-positive pelvic lymph nodes. In patients with postoperatively biochemical persistence, $\mathrm{PET} / \mathrm{CT}$ revealed a high number of lymph node metastases (58.3\%), distant metastases (23.3\%) and macroscopic residual tumour (21.7\%). Seventeen of 60 patients with persistent PSA after radical prostatectomy had a pre-PSMA PET/CT PSA $<0.5 \mathrm{ng} / \mathrm{ml}$. Of these patients, there was one patient $(5.9 \%)$ with macroscopic residual tumour, 7 patients with pelvic lymph node metastases (41.2\%) and 1 patient with distant metastases (5.9\%). The single patient with bone metastases had pelvic lymph node involvement as well. Figure 3 shows a lesion based analysis of PETpositive local recurrence/primary tumour, PET- 


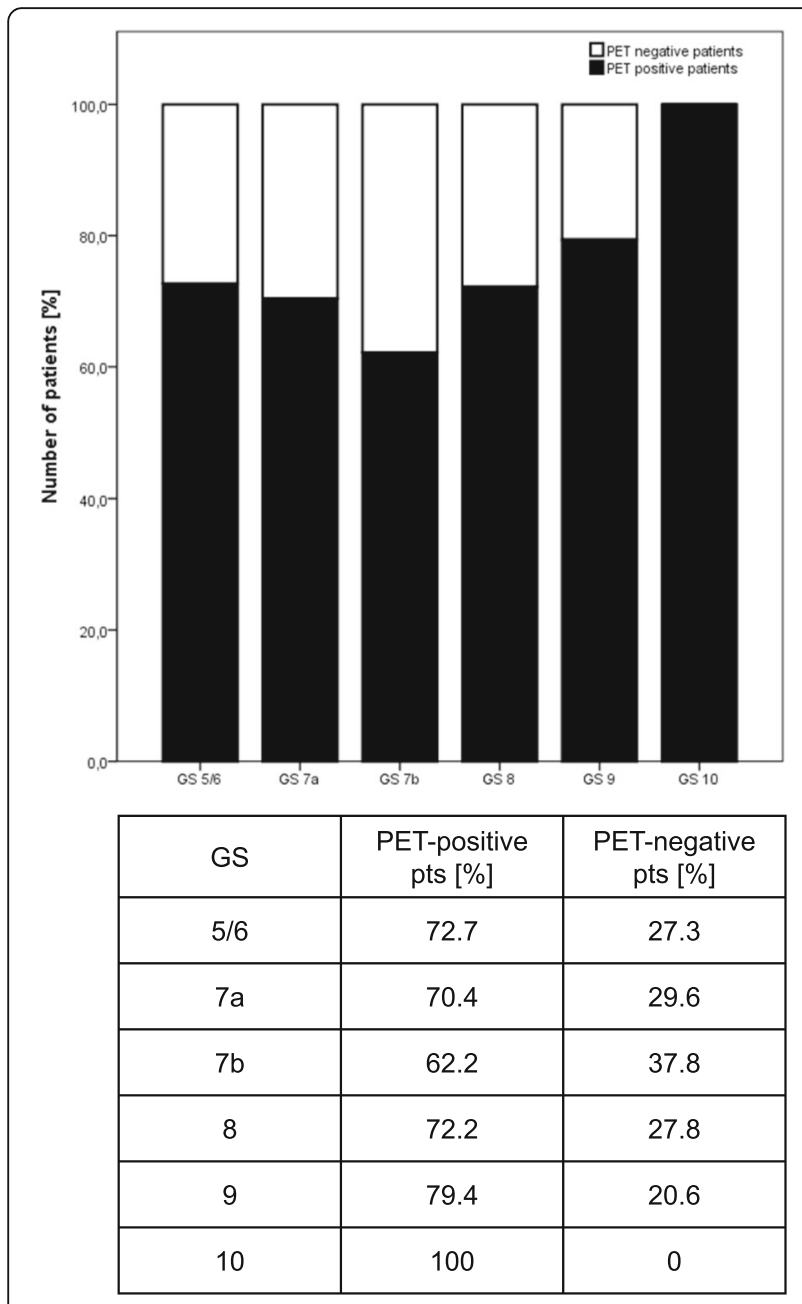

Fig. 2 Probability of a pathological ${ }^{68} \mathrm{Ga}$-PSMA PET/CT depending on GS in 129 patients. Corresponding table shows the rates of PET/CTS with/without pathological radiotracer uptake in \% according to GS class

positive lymph node and distant metastases according to sub-grouping of patients and contains additional information on simultaneous involvement of local recurrent tumour/primary tumour, lymph node metastases and/or distant metastases. ${ }^{68} \mathrm{Ga}$-PSMA PET/CT as medical imaging modality had a significantly higher diagnostic value in the detection of suspicious lesions within the prostate/prostatic fossa (38\% vs. 10.1\%; $p<0.05)$, of suspicious pelvic lymph nodes $(38.8 \%$ vs. $15.5 \% ; \mathrm{p}<0.05)$ and distant metastases $(14.0 \%$ vs. 5.4\%; $\mathrm{p}<0.05)$ compared to the contrast enhanced $\mathrm{CT}$ scan acquired during PET/CT imaging. This resulted in a modification of radiotherapy treatment in $56.6 \%$ of patients by e.g. enlarged target volumes or simultaneously integrated boost volumes. Figure 4 demonstrates the integration of ${ }^{68} \mathrm{Ga}$-PSMA PET/CT images into radiation therapy planning in three patients.

\section{Discussion}

This heterogeneous group of patients with primary, recurrent or persistent prostate cancer represents a typical cohort referred to radiation oncology departments. We are thus confident that our findings are of relevance in clinical practice.

In general, out of 129 patients with high-risk primary, persistent or recurrent prostate cancer, PSMA-PET revealed a least one relevant lesion in $71.3 \%$ of the cohort. This rate compares nicely to the number of PET-positive patients (82.8\%) in the study of AfsharOromieh et al. [16]: a similarly heterogeneous group of patients with progressive disease after initial treatment (e.g. radiotherapy and/or surgery; $n=292$ ), before initiation of local therapy $(n=27)$ or before therapy with radiolabelled PSMA ligands $(n=38)$ was analysed.

The clear correlation of PSA level and probability of detection was seen in our analysis (Fig. 1) as well as in the data provided by Ceci et al. [25] $(n=70)$, AfsharOromieh et al. [16] $(\mathrm{n}=292)$ and Eiber et al. [17]. Accordingly, patients with biochemical recurrence having the lowest PSA levels prior to PSMA PET/CT had the lowest detection rate $(55.1 \%)$ compared to patients with persistent $(75 \%)$ or primary prostate cancer $(100 \%)$.

At present, PSA levels $\leq 0.2 \mathrm{ng} / \mathrm{ml}$ are frequently judged in postoperative patients to be non-critical, nevertheless one-third of our patients (33.3\%) had PET-positive findings even below a PSA of $0.2 \mathrm{ng} / \mathrm{ml}$. This rate drastically increased up to $69.2 \%$ in patients with a PSA level between $0.51-1.0 \mathrm{ng} / \mathrm{ml}$. Thus, PSMA PET/CT detects early local recurrence or metastatic disease and possibly allows for a more effective and early treatment.

Apart from PSA-level before PET/CT, multivariate analysis detected no significant associations between a positive PSMA PET/CT and any of the other factors including $\mathrm{ADT}$, amount of injected tracer, PSA doubling time, and Gleason score. This finding is well in accordance with the observations provided by Afshar-Oromieh et al. [16] regarding PSA doubling time and Gleason score. In contrast, Afshar-Oromieh et al. reported a positive association between detection rate and ongoing ADT. In animal models and in vitro cell culture experiments, ADT increases PSMA expression which might contribute to improved detection rate by ${ }^{68} \mathrm{Ga}$-PSMA $\mathrm{PET} / \mathrm{CT}[26-30]$. However, at present the complex association between an ADT driven increase of PSMA uptake in the individual tumour lesion, the ADT driven reduction of global tumour load and the final PET signal is not completely understood. In our opinion, the use of ADT in a cohort with mostly high-risk prostate cancer patients as evaluated by Afshar-Oromieh et al. is also a surrogate for high tumour burden and high PSA levels. We therefore counsel our patients to start with 


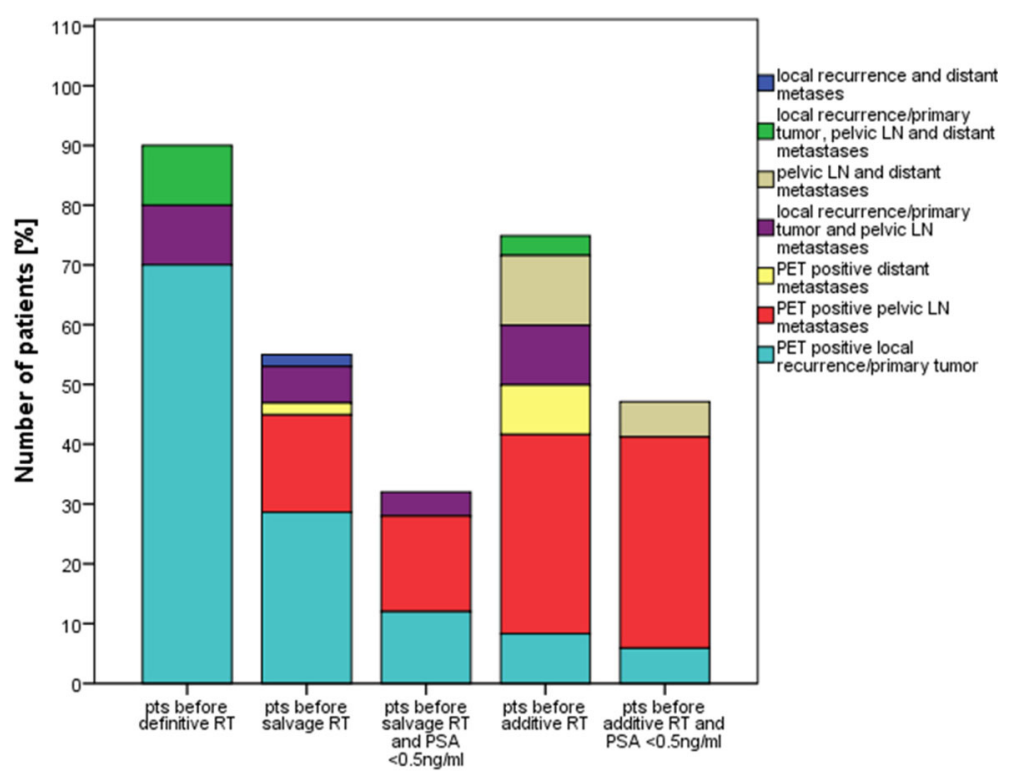

\begin{tabular}{|c|c|c|c|c|c|}
\hline & 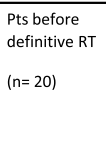 & Pts before salvage RT (n=49) & $\begin{array}{l}\begin{array}{l}\text { Pts before salvage RT } \\
\text { and PSA }<0.5 \mathrm{ng} / \mathrm{ml} \\
(\mathrm{n}=25)\end{array} \\
\end{array}$ & $\begin{array}{l}\text { Pts before } \\
\text { additive RT } \\
(n=60)\end{array}$ & \begin{tabular}{|l|} 
Pts before \\
additive RT \\
and PSA \\
$<0.5 \mathrm{ng} / \mathrm{ml}$ \\
$(\mathrm{n}=17)$
\end{tabular} \\
\hline \begin{tabular}{|l|} 
Local \\
recurrence/primary \\
tumor [\%] \\
\end{tabular} & 70 & 28,6 & 12 & 8,3 & 5,9 \\
\hline $\begin{array}{l}\text { Pelvic LN metastases } \\
\text { [\%] }\end{array}$ & & 16,3 & 16 & 33,3 & 35,3 \\
\hline 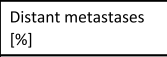 & & 2,0 & & 8,3 & \\
\hline \begin{tabular}{|l|} 
Local \\
recurrence/primary \\
tumor and pelvic LN \\
metastases [\%] \\
\end{tabular} & 10 & 6,1 & 4 & 10,0 & \\
\hline \begin{tabular}{|l}
$\begin{array}{l}\text { Pelvic } L N \text { and distant } \\
\text { metastases [\%] }\end{array}$ \\
\end{tabular} & & & & 11,7 & 5,9 \\
\hline \begin{tabular}{|l|} 
Local \\
recurrence/primary \\
tumor, pelvic LN and \\
distant metastases \\
[\%] \\
\end{tabular} & 10 & & & 3,3 & \\
\hline $\begin{array}{l}\text { Local recurrence and } \\
\text { distant metastases } \\
[\%]]\end{array}$ & & 2,0 & & & \\
\hline
\end{tabular}

Fig. 3 Lesion based analysis (PET-positive local recurrence/primary tumour and PET-positive lymph node and distant metastases) according to sub-grouping of patients (patients before definitive RT at initial diagnosis, patients before salvage RT with PSA recurrence, patients before Salvage RT with PSA $<0.5 \mathrm{ng} / \mathrm{ml}$, patients before additive RT with PSA persistence, patients before additive RT with PSA persistence with PSA $<0.5 \mathrm{ng} / \mathrm{ml}$ )

ADT after PSMA PET/CT if planned. Unlike the aforementioned trials, Ceci et al. also observed a significant association between PSA doubling time and PSMA PET/CT positivity [25]. This might be explained by the fact that Ceci et al. coded PSA doubling time as continuous variables whereas in our trial and the trial of Afshar-Oromieh et al. PSA doubling time was analysed in distinct categories.

Compared to CT, sensitivity of PSMA PET/CT was significantly higher for local findings $(38.0 \%$ vs. $10.1 \%)$, pelvic lymph nodes $(38.8 \%$ vs. $15.5 \%)$ and distant failure $(14.0 \%$ vs. $5.4 \%)$. This observation perfectly mirrors the findings reported by Giesel el al. showing that PSMA PET/CT is significantly more sensitive than CT-based 3D-volumetric lymph node evaluation [18].

Furthermore, we analysed the question how far an increased detection rate leads to a change in therapeutic management. In our series, PSMA PET/CT-positive findings had a substantial influence on the therapeutic concept in $56.6 \%$ of the patients with implication on either adaptation of treatment volumes, dose concepts or the commencement of hormone ablation therapy. This compares nicely to similar analyses [19, 31-33] all 

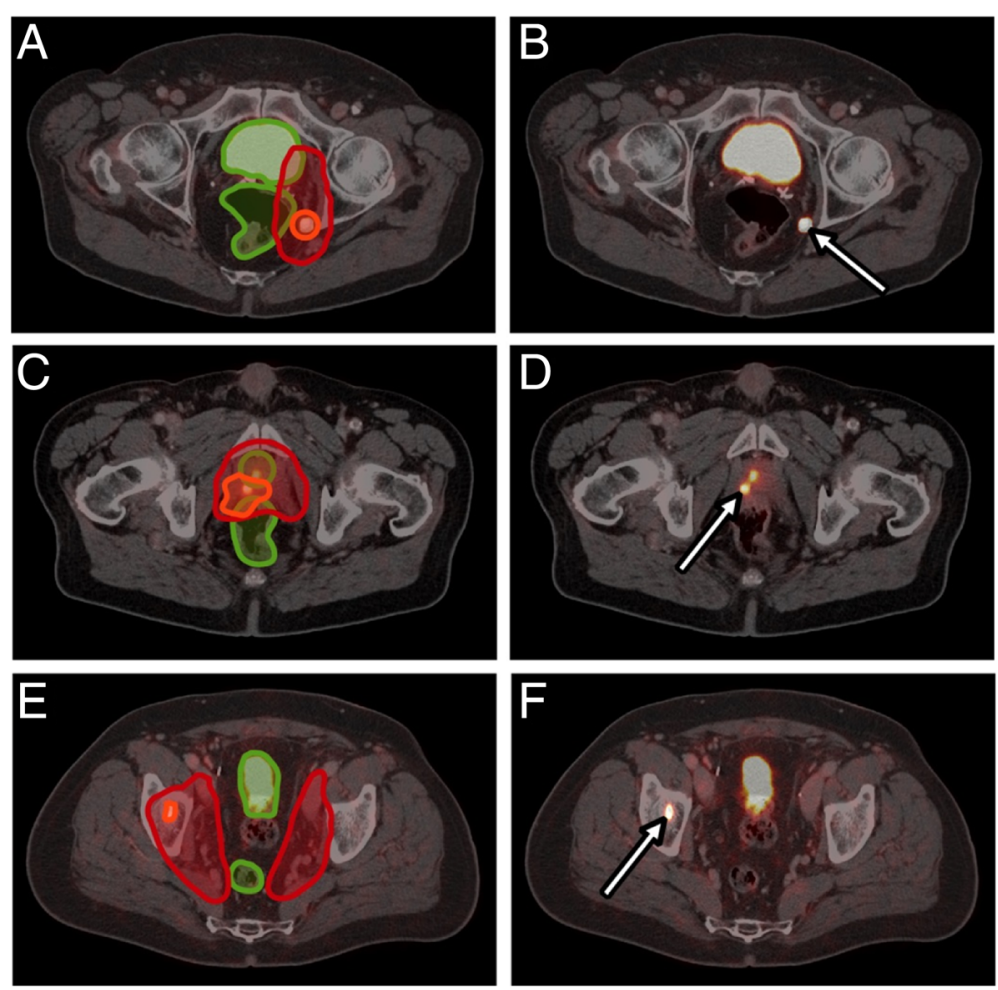

Fig. 4 Radiotherapy treatment planning in three patients based on PSMA PET/CT information. ${ }^{68} \mathrm{Ga}$-PSMA PET/CT (B, D, F) and target volumes with simultaneously integrated boost volumes $(\mathbf{A}, \mathbf{C}, \mathbf{E})$ are shown. Figs. $\mathbf{A}$ and $\mathbf{B}$ show a patient with PSA recurrence and evidence of lymph node metastasis in ${ }^{68} \mathrm{Ga}$-PSMA PET/CT who was treated with a simultaneously integrated boost to the lymph node. Figs. $\mathbf{C}$ and $\mathbf{D}$ show a patient with PSA recurrence due to local relapse in the region of the former prostate gland. This local relapse was treated with a simultaneously integrated boost volume. Figs. $\mathbf{F}$ and $\mathbf{E}$ show a patient with singular osseous metastasis that was treated with a simultaneously integrated boost

reporting major modifications of therapeutic management in $33.3 \%-53.7 \%$ of the patients.

At present, PSMA PET/CT is widely regarded as the best modality for lymph node staging in a primary as well as in a postoperative setting [14, 34]. Data provided by van Leeuwen et al. [19] suggest that the level of lymph node positivity has been strongly underestimated in the pre-PSMA PET/CT era. In their analysis, lymphatic recurrences outside the prostatic fossa occurred in $20 \%$ of patients scheduled for salvage radiotherapy with additional $10 \%$ of distant metastases detected in PSMA PET/CT. Bearing in mind that currently only target volumes covering the prostatic fossa are routinely employed [35], a substantial rate of lymph node metastases is not treated. This is supported by our own data showing that even below a PSA level of $0.5 \mathrm{ng} / \mathrm{ml}$, PSMA PET/CT still detected $20.0 \%$ of pelvic lymph node metastases in patients with salvage radiotherapy indication.

The documented need to treat PSA relapses as early as possible (even below PSA levels of $0.2 \mathrm{ng} / \mathrm{ml}$ ) and the fact that the diagnostic sensitivity is optimal above a PSA level of $0.5 \mathrm{ng} / \mathrm{ml}$ currently creates an inherent dilemma. Since all data available consistently document that PSA control is significantly better when radiotherapy is commenced as early as possible [36, 37], it is not justified to wait until PSA is in an optimal diagnostic range. Our strategy to cope with this dilemma is therefore to employ PSMA $\mathrm{PET} / \mathrm{CT}$ in patients even around $0.2 \mathrm{ng} / \mathrm{ml}$ especially whenever high-risk features are present. Like the analysis by Henkenberens et al. on 29 patients with biochemical recurrence receiving an individualized radiotherapy treatment plan based on PSMA PET/CT findings [38], target volumes are modified accordingly in our institution after critical assessment. Nevertheless, keeping the sensitivity and specificity rates from surgical series in mind, PSMA PET/CT might still underestimate the true extent of disease and should therefore from our point of view not result in an omission of nomogram [39] triggered radiotherapy treatment volumes.

At present, legal constraints prohibit the use of PSMA in truly prospective studies in Germany. Despite the clear limitations of retrospective approaches, the available data from several analyses strongly underline the high value of PSMA-PET/CT for staging as well as for treatment stratification in patients with primary high-risk, persistent or recurrent carcinoma of the prostate. 


\section{Conclusions}

In this retrospective study, we showed that the detection of prostate cancer is strongly associated with PSA level at time of Ga-PSMA PET/CT. Better than any other imaging modality, PSMA PET/CT differentiates local, regional and distant metastatic disease with considerable implications for disease management. In post-prostatectomy patients with rising PSA $\leq 0.5 \mathrm{ng} / \mathrm{ml}$ with indication for salvage radiotherapy, PSMA PET/CT is narrowing the diagnostic gap as until now the gradual PSA increase often occurred long before recurrent disease could be localized clinically or by imaging.

\section{Abbreviations}

ADT: androgen deprivation therapy; GS: Gleason score; MBq: megabecquerel; PCa: prostate cancer; PET: positron emission tomography; PET/CT: positron emission tomography/computed tomography; PSMA: prostate-specific membrane antigen; Pts: patients; RT: radiotherapy

\section{Acknowledgements}

Not applicable.

\section{Funding}

No funding was received.

\section{Availability of data and materials}

The datasets used and analysed during the current study are available from the corresponding author on reasonable request.

\section{Authors' contributions}

N-S S-H, WPF, and UG analysed and interpreted the data, performed the statistical analysis and were major contributors in writing and revising the manuscript. Thus, $\mathrm{N}-\mathrm{S}$ S-H and WPF are equally contributing first authors. $C B$ and $A B$ helped with the statistical analysis and writing the manuscript. CS, PR, MN, CE, ML and PB have revised the manuscript critically for important intellectual content. All authors read and approved the final manuscript.

\section{Ethics approval and consent to participate}

All patients gave written consent to undergo ${ }^{68} \mathrm{Ga}$-PSMA PET/CT. This retrospective analysis is in compliance with the principles of the Declaration of Helsinki and its subsequent amendments [21] and was approved by the Ethics Committee of the LMU Medical Faculty.

\section{Consent for publication}

Not applicable.

\section{Competing interests}

The authors declare that they have no competing interests.

\section{Publisher's Note}

Springer Nature remains neutral with regard to jurisdictional claims in published maps and institutional affiliations.

\section{Author details}

'Department of Radiation Oncology, University Hospital, LMU Munich, Munich, Germany. ${ }^{2}$ Department of Nuclear Medicine, University Hospital, LMU Munich, Munich, Germany. ${ }^{3}$ Department of Urology, University Hospital, LMU Munich, Munich, Germany. ${ }^{4}$ Department of Therapeutic Radiology and Oncology, Innsbruck Medical University, Anichstr. 35, A-6020 Innsbruck, Austria.
Received: 1 August 2017 Accepted: 25 October 2017

Published online: 10 November 2017

\section{References}

1. Heidenreich A, Bastian PJ, Bellmunt J, Bolla M, Joniau S, van der Kwast T, et al. EAU guidelines on prostate cancer. Part II: treatment of advanced, relapsing, and castration-resistant prostate cancer. Eur Urol. 2014;65(2):467-79.

2. Schiller K, Sauter K, Dewes S, Eiber M, Maurer T, Gschwend J, Combs SE, et al. Patterns of failure after radical prostatectomy in prostate cancer implications for radiation therapy planning after (68)Ga-PSMA-PET imaging. Eur J Nucl Med Mol Imaging. 2017; doi: 10.1007/s00259-017-3746-9.

3. Afshar-Oromieh A, Zechmann C, Malcher A, Eder M, Eisenhut M, Linhart $H$, et al. Comparison of PET imaging with a 68Ga-labelled PSMA ligand and 18F-choline-based PET/CT for the diagnosis of recurrent prostate cancer. EJNMMI. 2014:41(1):11-20.

4. Vargas HA, Martin-Malburet AG, Takeda T, Corradi RB, Eastham J, Wibmer A, et al. Localizing sites of disease in patients with rising serum prostatespecific antigen up to $1 \mathrm{ng} / \mathrm{ml}$ following prostatectomy: how much information can conventional imaging provide? Urol Oncol-Semin Orig Investig. 2016;34(11):482.e485-482.e410

5. Panje C, Panje T, Putora PM, Kim SK, Haile S, Aebersold DM, et al. Guidance of treatment decisions in risk-adapted primary radiotherapy for prostate cancer using multiparametric magnetic resonance imaging: a single center experience. Radiat Oncol. 2015:10(1):47.

6. Hernandez D, Salas D, Giménez D, Buitrago P, Esquena S, Palou J, et al. Pelvic MRI findings in relapsed prostate cancer after radical prostatectomy. Radiat Oncol. 2015;10(1):262.

7. Gupta M, Choudhury PS, Hazarika D, Rawal SA. Comparative study of (68)gallium-prostate specific membrane antigen positron emission tomography-computed tomography and magnetic resonance imaging for lymph node staging in high risk prostate cancer patients: an initial experience. World J Nucl Med. 2017;16(3):186-91.

8. Afshar-Oromieh A, Malcher A, Eder M, Eisenhut M, Linhart HG, Hadaschik BA, et al. PET imaging with a 68Ga-labelled PSMA ligand for the diagnosis of prostate cancer: biodistribution in humans and first evaluation of tumour lesions. EJNMMI. 2013;40:797-8.

9. Eder M, Schafer M, Bauder-Wust U, Hull WE, Wangler C, Mier W, et al. 68Gacomplex lipophilicity and the targeting property of a urea-based PSMA inhibitor for PET imaging. Bioconjug Chem. 2012;23:688-97.

10. Sweat SD, Pacelli A, Murphy GP, Bostwick DG. Prostate-specific membrane antigen expression is greatest in prostate adenocarcinoma and lymph node metastases. Urology. 1998;52:637-40.

11. Silver DA, Pellicer I, Fair WR, Heston WD, Cordon-Cardo C. Prostate-specific membrane antigen expression in normal and malignant human tissues. Clin Cancer Res. 1997;3(1):81-5

12. Fendler WP, Schmidt DF, Wenter V, Thierfelder KM, Zach C, Stief C, et al. 68Ga-PSMA-HBED-CC PET/CT detects location and extent of primary prostate cancer. J Nucl Med. 2016:57:1720-5.

13. Eiber M, Weirich G, Holzapfel K, Souvatzoglou M, Haller B, Rauscher I, et al. Simultaneous (68)Ga-PSMA HBED-CC PET/MRI improves the localization of primary prostate cancer. Eur Urol. 2016;70(5):829-36.

14. Maurer T, Gschwend JE, Rauscher I, Souvatzoglou M, Haller B, Weirich G, et al. Diagnostic efficacy of (68)Gallium-PSMA positron emission tomography compared to conventional imaging for lymph node staging of 130 consecutive patients with intermediate to high risk prostate cancer. J Urol. 2016;195(5):1436-43.

15. Herlemann A, Wenter V, Kretschmer A, Thierfelder KM, Bartenstein P, Faber C, et al. (68)Ga-PSMA positron emission tomography/computed tomography provides accurate staging of lymph node regions prior to lymph node dissection in patients with prostate cancer. Eur Urol. 2016;70:553-7.

16. Afshar-Oromieh A, Avtzi E, Giesel F, Holland-Letz T, Linhart H, Eder M, et al. The diagnostic value of PET/CT imaging with the 68Ga-labelled PSMA ligand HBED-CC in the diagnosis of recurrent prostate cancer. EJNMMI. 2015;42(2):197-209.

17. Eiber M, Maurer T, Souvatzoglou M, Beer AJ, Ruffani A, Haller B. Evaluation of hybrid 68Ga-PSMA-Ligand PET/CT in 248 patients with biochemical recurrence after radical prostatectomy. J Nucl Med. 2015;56:668-74.

18. Giesel F, Fiedler $H$, Stefanova $M$, Sterzing F, Rius M, Kopka $K$, et al. PSMA PET/CT with Glu-urea-Lys-(Ahx)-[68Ga(HBED-CC)] versus 3D CT volumetric lymph node assessment in recurrent prostate cancer. EJNMMI. 2015;42(12):1794-800. 
19. van Leeuwen PJ, Stricker P, Hruby G, Kneebone A, Ting F, Thompson B, et al. (68) Ga-PSMA has a high detection rate of prostate cancer recurrence outside the prostatic fossa in patients being considered for salvage radiation treatment. BJU Int 2016; 117(5):732-739.

20. Afshar-Oromieh A, Holland-Letz T, Giesel FL, Kratochwil C, Mier W, Haufe S, et al. Diagnostic performance of (68)Ga-PSMA-11 (HBED-CC) PET/CT in patients with recurrent prostate cancer: evaluation in 1007 patients. EJNMMI. 2017:44(8):1258-68.

21. General Assembly of the World Medical Association. World medical association declaration of Helsinki: ethical principles for medical research involving human subjects. J Am Coll Dent. 2014;81(3):14-8.

22. Weineisen M, Simecek J, Schottelius M, Schwaiger M, Wester H-J. Synthesis and preclinical evaluation of DOTAGA-conjugated PSMA ligands for functional imaging and endoradiotherapy of prostate cancer. EJNMMI Res. 2014:4(1):1-15.

23. Clinical Practice Guidelines in Oncology: Prostate Cancer. V.1.2015. http://www. nccn.org/professionals/physician_gls/pdf/prostate.pdf. Accessed 30 Dec 2015

24. D'Amico AV, Whittington R, Malkowicz SB, Weinstein M, Tomaszewski JE, Schultz D, et al. Predicting prostate specific antigen outcome preoperatively in the prostate specific antigen era. J Urol. 2001;166:2185-8.

25. Ceci F, Uprimny C, Nilica B, Geraldo L, Kendler D, Kroiss A, et al. (68)GaPSMA PET/CT for restaging recurrent prostate cancer: which factors are associated with PET/CT detection rate? EJNMMI. 2015;42(8):1284-94.

26. Evans MJ, Smith-Jones PM, Wongvipat J, Navarro V, Kim S, Bander NH, Larson SM, et al. Noninvasive measurement of androgen receptor signaling with a positron-emitting radiopharmaceutical that targets prostate-specific membrane antigen. Proc Natl Acad Sci. 2011;108(23):9578-82.

27. Murga JD, Moorji SM, Han AQ, Magargal WW, DiPippo VA, Olson WC. Synergistic co-targeting of prostate-specific membrane antigen and androgen receptor in prostate cancer. Prostate. 2015;75(3):242-54

28. Liu T, Wu LY, Fulton MD, Johnson JM, Berkman CE. Prolonged androgen deprivation leads to downregulation of androgen receptor and prostate-specific membrane antigen in prostate cancer cells. Int J Oncol. 2012;41(6):2087-92

29. Hope TA, Truillet C, Ehman EC, Afshar-Oromieh A, Aggarwal R, Ryan CJ, et al. 68Ga-PSMA-11 PET imaging of response to androgen receptor inhibition: first human experience. J Nucl Med. 2017:58(1):81-4.

30. Wright GL Jr, Mayer Grob B, Haley C, Grossman K, Newhall K, Petrylak D, et al. Upregulation of prostate-specific membrane antigen after androgendeprivation therapy. Urology. 1996:48(2):326-34.

31. Shakespeare TP. Effect of prostate-specific membrane antigen positron emission tomography on the decision-making of radiation oncologists. Radiat Oncol. 2015;10(1):1-4.

32. Dewes S, Schiller K, Sauter K, Eiber M, Maurer T, Schwaiger M, et al. Integration of (68)Ga-PSMA-PET imaging in planning of primary definitive radiotherapy in prostate cancer: a retrospective study. Radiat Oncol. 2016;11:73.

33. Sterzing F, Kratochwil C, Fiedler H, Katayama S, Habl G, Kopka K, et al. 68GaPSMA-11 PET/CT: a new technique with high potential for the radiotherapeutic management of prostate cancer patients. EJNMMI. 2015:1-8.

34. Perera M, Papa N, Christidis D, Wetherell D, Hofman MS, Murphy DG, et al. Sensitivity, specificity, and predictors of positive 68Ga-prostate-specific membrane antigen positron emission tomography in advanced prostate cancer: a systematic review and meta-analysis. Eur Urol. 2016;70(6):926-37.

35. Bell $L$, Cox J, Eade T, Rinks M, Herschtal A, Kneebone A. Determining optimal planning target volume and image guidance policy for post-prostatectomy intensity modulated radiotherapy. Radiat Oncol. 2015;10(1):151.

36. Tendulkar RD, Agrawal S, Gao T, Efstathiou JA, Pisansky TM, Michalski $\mathrm{JM}$, et al. Contemporary update of a multi-institutional predictive Nomogram for salvage radiotherapy after radical prostatectomy. J Clin Oncol. 2016;34(30):3648-54.

37. Pfister D, Bolla M, Briganti A, Carroll P, Cozzarini C, Joniau S, et al. Early salvage radiotherapy following radical prostatectomy. Eur Urol. 2014;65(6):1034-43.

38. Henkenberens $C$, von Klot CA, Ross TL, Bengel FM, Wester HJ, Merseburger AS, et al. (68)Ga-PSMA ligand PET/CT-based radiotherapy in locally recurrent and recurrent oligometastatic prostate cancer : early efficacy after primary therapy. Strahlenther Onkol 2016; 192(7):431-439.

39. Wu R, Woodford H, Capp A, Hunter P, Cowin G, Tai K-H, et al. A prospective study of nomogram-based adaptation of prostate radiotherapy target volumes. Radiat Oncol. 2015:10(1):243.

\section{Submit your next manuscript to BioMed Central and we will help you at every step:}

- We accept pre-submission inquiries

- Our selector tool helps you to find the most relevant journal

- We provide round the clock customer support

- Convenient online submission

- Thorough peer review

- Inclusion in PubMed and all major indexing services

- Maximum visibility for your research

Submit your manuscript at www.biomedcentral.com/submit
) Biomed Central 